Gut, 1981, 22, 566-570

\title{
In vitro studies on cellular and humoral chemotaxis in Crohn's disease using the under agarose gel technique*
}

\author{
R D'AMELIO, P ROSSI, S LE MOLI, R RICCI, S MONTANO, AND F PALLONE † \\ From the Departments of Medicine 3rd, Paediatrics 1st, Clinical Immunology and Gastroenterology, \\ University of Rome, Rome, Italy
}

SUMMARY The locomotor function of polymorphonuclear cells (cellular chemotaxis) and serum chemotactic activity (humoral chemotaxis) were studied in 51 patients with Crohn's disease using a method of migration under agarose gel. To study cellular chemotaxis patient's polymorphonuclear cells were challenged against normal Zymosan activated serum and humoral chemotaxis was evaluated testing the patient's Zymosan activated serum against normal polymorphonuclear cells. Cellular chemotaxis in the Crohn's disease group was normal (although $30 \%$ of the 51 patients had migration values out of the normal range), while humoral chemotaxis was significantly lower in Crohn's disease patients than in the control group. However, the value of humoral chemotaxis in the group of Crohn's disease patients treated with steroids was lower than that of patients not treated, thus accounting for the low mean value observed in the Crohn's disease group as a whole. The present results suggest that a defective chemotactic response may occur in some Crohn's disease patients, particularly during steroid treatment. These findings might be related either to a defective generation of complement derived chemotactic factors or to the presence of circulating inhibitors.

Leucocyte chemotaxis is one of the early stages of the phagocytic process which is the basic mechanism in the clearance of particulate or antigenic materials.

In Crohn's disease a defective clearance has been suggested as one of the underlying pathogenetic mechanisms of the chronic inflammation. ${ }^{1}$ Furthermore, the high prevalence of abscesses and fistulae in this condition suggests that defects in local defence mechanisms may occur during the natural history of the disease.

In studies using the skin window technique, Segal and Loewi ${ }^{2}$ reported in Crohn's disease a defective neutrophil function 'in vivo.' They found, however, a normal neutrophil chemotaxis 'in vitro' by a modified Boyden chamber technique. Later, Rhodes and Jewell ${ }^{3}$ confirmed normal chemotaxis 'in vitro' using a different method of migration through millipore filters.

*Supported in part by grant CNR no. 75.00879.04/115.8474 to FP.

†Address for correspondence and reprints requests: F Pallone, Gastroenterology Unit, 2 Clinica Medica, Università, viale del Policlinico, 00161 Roma, Italy.

Received for publication 20 January 1981
In the present investigation the locomotor function of polymorphonuclear cells (cellular chemotaxis) as well as the complement derived serum chemotactic activity (humoral chemotaxis) were studied in Crohn's disease patients using a new method ${ }^{4}$ of migration under agarose gel.

As we have already described ${ }^{45}$ a defective chemotactic function in patients with hypogammaglobulinaemia and/or IgA deficiency, the serum immunoglobulin levels were also considered in the study.

\section{Methods}

PATIENTS

Fifty-one patients with Crohn's disease, 30 male and 21 female, with a mean age of $36 \cdot 3$ years, were included in the study. Diagnosis was based on typical clinical and radiological findings and confirmed by histology in 28 patients. The mean duration of symptoms was five years. The disease involved the ileum (either as a primary or recurrent disease) in 33 patients, the ileum and colon in 13 , and the colon only in five. Crohn's Disease Activity Index (CDAI) as proposed by the National Cooperative Crohn's 
Disease Study (NCCDS), USA ${ }^{6}$ was used to evaluate disease activity.

Medical treatment, when given, consisted of corticosteroids and/or sulphasalazine (Salazopyrin (SAP)). Twenty-nine patients were receiving corticosteroids at the time of the study: mean dose $17 \mathrm{mg} /$ day prednisone (range 5-25 mg) for a mean period of 5.5 months (range three to 10). Nine of these patients were also receiving SAP. Four patients were receiving only SAP at the time of the study. Local complications were present in 16 patients: enterocutaneous fistulae, eight; enteroenteric fistulae, three; obstruction, two; anal lesions, three; abscesses, two. Two patients had systemic complications: ankylosing spondylitis, one, and pyoderma gangrenosum, one.

\section{CONTROLS}

Fifty-one healthy volunteers of comparable age and sex distribution were studied as a control group. An additional 12 patients with different chronic diseases (ulcerative colitis, five; chronic active hepatitis, two; systemic lupus erythematosus, three; asthma, two) chronically treated with steroids were also considered.

The results of liver function tests were within the normal ranges in all patients and control subjects.

\section{Cell isolation}

Samples of $10 \mathrm{ml}$ heparinised sterile blood were centrifuged at $200 \mathrm{~g}$ for 15 minutes in polystyrene test tubes. The plasma and buffy coat leucocytes were transferred to another tube and separated by gravity sedimentation at $37^{\circ} \mathrm{C}$ in a mixture of air $(95 \%)$ and $\mathrm{CO}_{2}(5 \%)$ for 45 minutes. The leucocyte-rich supernatant was then layered on Ficoll-Isopaque density gradient and centrifuged at $900 \mathrm{~g}$ for 30 minutes. The PMN were collected from the bottom and resuspended in $3 \mathrm{ml}$ of medium (TC 199, RPMI 1640, Flow Laboratories). The cells were washed twice and the erythrocyte contamination was eliminated by lysis with buffered ammonium chloride. The cells were finally resuspended at a concentration of $30 \times 10^{6} / \mathrm{ml}$. The medium used for resuspension was the same as that used for preparation of agarose plates.

\section{Collection of serum and activation}

Both plasma EDTA and fresh serum samples were collected. For activation the fresh serum was incubated for 30 minutes at $37^{\circ} \mathrm{C}$ with Zymosan (Sigma Chemical Co) $50 \mathrm{mg} / \mathrm{ml}$. It was then centrifuged at $700 \mathrm{~g}$ for 10 minutes and the supernatant collected.

\section{Preparation of agarose plates}

Agarose (Reo 15, Boehring) was dissolved in TC 199 or RPMI 1640 by heating in a boiling water bath at a concentration of $1 \cdot 2 \%$. After cooling to $45^{\circ}-50^{\circ} \mathrm{C}$, the agarose medium was supplemented with $10 \%$ of fetal calf serum (Colorado serum $\mathrm{Co}$ ) and 1.5 of this solution was poured into a $35 \mathrm{~mm}$ tissue culture dish (3001, Falcon) and allowed to harden. Three wells (4 $\mathrm{mm}$ in diameter and spaced $2 \mathrm{~mm}$ apart) were cut, using a suitable template punch prepared by us. The agarose plugs were removed by means of a Pasteur pipette attached to a vacuum line.

\section{Leucocyte chemotaxis assay}

The tests were carried out in duplicate: $10 \mu$ l of the cell suspension was added to the central well and $10 \mu \mathrm{l}$ of activated serum to one of the lateral wells. The other wells was filled with $10 \mu$ of TC 199 or RPMI 1640. The dishes were covered and placed in a $37^{\circ} \mathrm{C}$ humid atmosphere with $5 \%$ of $\mathrm{CO}_{2}$ for three hours. The preparations were then fixed with May-Grunwald for 30 minutes, the layer of the agarose was removed, and the plates stained with Giemsa. The migrated cells were counted in a Leitz Orthoplan microscope using $\times 10$ eye-piece grid (side $1 \mathrm{~cm}$ ) with a $\times 10$ magnification. The number of cells which had migrated towards the non-attracting pole, which are considered to have undergone random locomotion, was subtracted. After the preparation had been projected with a Leitz microprojector (magnification scale 1:175) the maximum distance of migration was measured and the distance of random locomotion was subtracted. The measurement was then multiplied by the number of cells and divided by 100 . The Migration Index (MI) was then calculated by the following formula:

$\frac{(\text { no. chem. cells }- \text { no. rm cells }) \times(\text { chem. } d-\text { rmd })}{100}=M I$

The random migration index (RMI) was calculated as:

$$
\frac{\text { number } \mathrm{rm} \text { cells } \times \text { rmd }}{100}=\mathrm{RMI}
$$

where: chem $. \mathrm{d}=$ maximum migration distance $; \mathrm{rmd}=$ distance of random migration; chem. cells $=\mathrm{PMN}$ chemotaxis migrated; $\mathrm{rm}$ cells $=\mathrm{PMN}$ randomly migrating.

Using this leucocyte chemotaxis assay we evaluated the cellular chemotactic function by testing the patients PMN against normal Zymosan activated serum (ZAS). To study the humoral chemotaxisthat is, the generation of complement derived serum chemotactic factors-normal PMN were challenged against patient's ZAS.

\section{Complement and immunoglobulin assay}

Plasma EDTA C3 $3_{c}$ and $\mathrm{C} 4$ levels and serum immunoglobulins A, G, M were detected by the method of 
Table Values (mean $\pm S D$ ) of migration index for cellular and humoral chemotaxis in control subjects and Crohn's disease

\begin{tabular}{|c|c|c|c|c|c|c|}
\hline & \multirow[t]{2}{*}{ Control } & & \multicolumn{4}{|c|}{ Crohn's disease } \\
\hline & & & Patients & Treated & & Untreated \\
\hline $\begin{array}{l}\text { Cellular chemotaxis } \\
\text { Humoral chemotaxis }\end{array}$ & $\begin{array}{l}492 \pm 205 \\
492 \pm 205\end{array}$ & $\underset{P<0 \cdot 01}{N S}$ & $\begin{array}{l}477 \pm 413 \\
372 \pm 242\end{array}$ & $\begin{array}{l}482 \pm 426 \\
297 \pm 233\end{array}$ & $\underset{\mathrm{P}<0 \cdot \mathbf{0 2}}{\mathrm{NS}}$ & $\begin{array}{l}470 \pm 405 \\
458 \pm 225\end{array}$ \\
\hline
\end{tabular}

Mancini et al. The $\mathrm{C} 3_{\mathrm{c}}$ was evaluated using a specific antiserum (Boehring-werke). The immunoglobulin and complement assays were performed in 48 patients.

For the statistical analysis of the data Student's $t$ test was used.

\section{Results}

No significant difference was found between healthy controls and Crohn's disease patients as far as the mean values of polymorphonuclear cellular chemotaxis are concerned (Table 1). However nine out of the 51 Crohn's disease patients had a migration index below the lower normal limit, while, in seven patients, a migration index above the upper normal limit was observed (Fig. 1). No correlation was found between cellular chemotaxis values and site and extent of

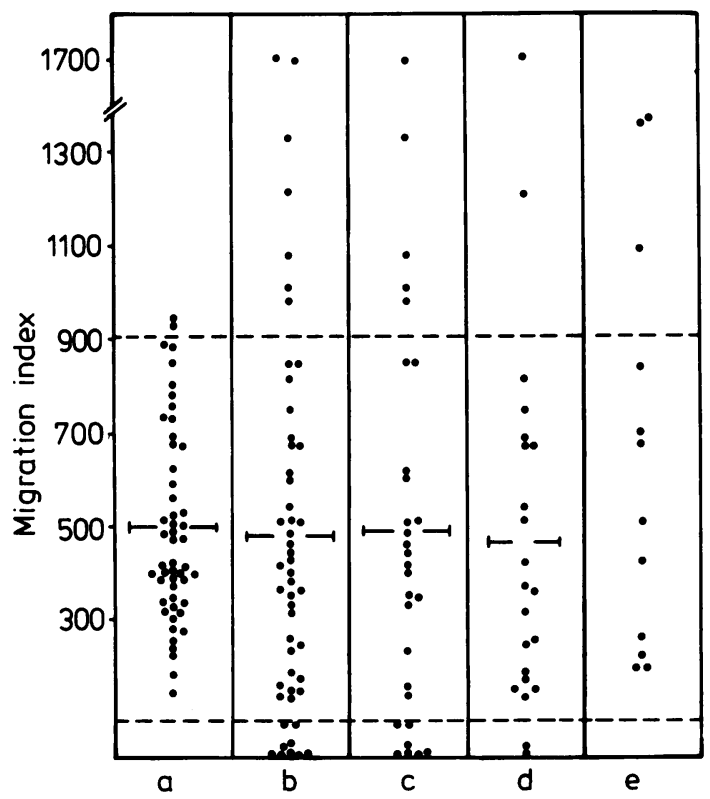

Fig. 1 Values of polymorphonuclear cellular chemotaxis expressed as Migration Index (MI). Horizontal bars indicate mean values. .... normal limits (mean $\pm 2 S D)$. a: healthy controls; $b$ : whole Crohn's disease group; $c$ : steroid treated Crohn's disease patients; $d$ : untreated Crohn's disease patients; $e$ : steroid treated controls. bowel involvement, disease activity, and occurrence of complications. Seven out of nine Crohn's disease patients with low values were receiving steroid treatment at the time of the study. No low values were found in the steroid treated control group.

The mean values of humoral chemotaxis - that is, complement derived serum chemotactic activitywere significantly lower in Crohn's disease patients than in the healthy controls (Table). Again, no significant correlation was found between migration index and disease activity, occurrence of complications, and site of bowel involvement. However when the humoral chemotaxis values were correlated with the medical treatment (Fig. 2) a significantly lower mean value of migration index was observed in the steroid treated Crohn's disease patients.

The mean values of $\operatorname{IgG}, \operatorname{IgA}$, and $\operatorname{IgM}$ were not significantly different from those of the normal

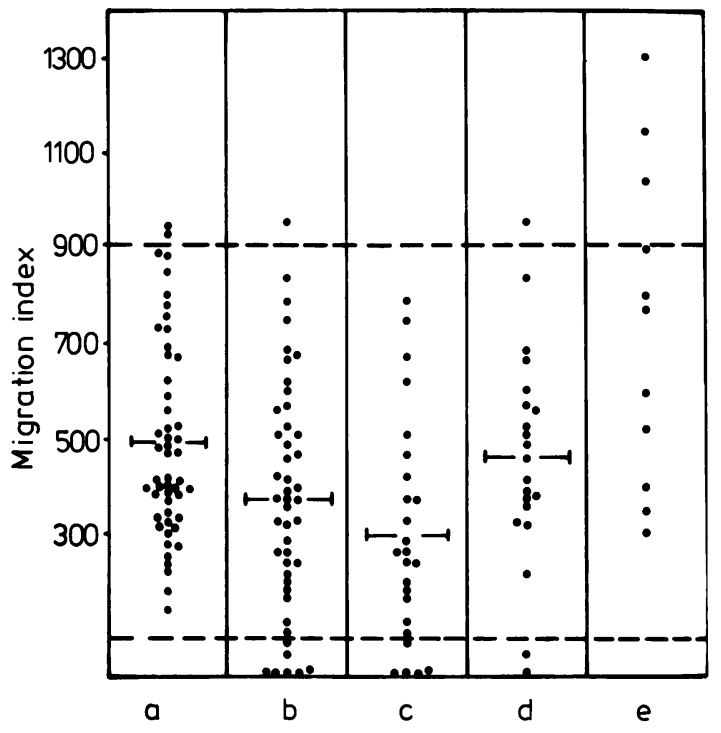

Fig. 2 Values of polymorphonuclear humoral chemotaxis expressed as Migration Index (MI). Horizontal bars indicate mean values. .... normal limits (mean $\pm 2 S D)$. a: healthy controls; $b$ : whole Crohn's disease group; $c$ : steroid treated Crohn's disease patients; $d$ : untreated Crohn's disease patients; $\mathrm{e}$ : steroid treated controls. $\mathrm{P}<0 \cdot 01$, b vs a; $\mathrm{P}<0 \cdot 02, \mathrm{~d}$ vs c. 


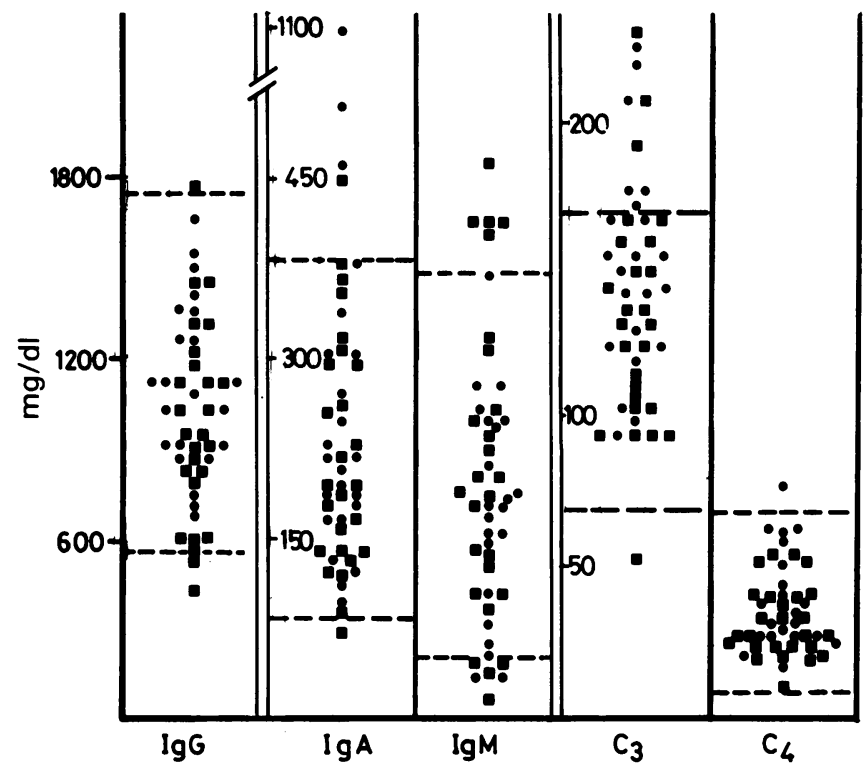

Fig. 3 Serum immunoglobulins and $C_{3}$ and $C_{4}$ levels in 49 Crohn's disease patients. - untreated patients. 1 steroid treated patients. .... normal limits.

controls. No significant difference was found between steroid treated and non-treated patients, as far as the serum Ig levels were concerned (Fig. 3).

Mean values of plasma EDTA C3c were normal, although nine out of 48 patients had $C 3_{c}$ levels above the upper normal limit. C4 levels were within the normal range in all patients (Fig. 3).

\section{Discussion}

The results of this study show that in Crohn's disease patients mean values of polymorphonuclear cellular chemotaxis were normal (although about $30 \%$ values were not within the normal range), while humoral chemotaxis values-that is, complement derived serum chemotaxis activity-were significantly lower than those of healthy controls. In fact, impaired humoral chemotaxis occurred mostly in the steroid treated patients, thus accounting for the low mean value observed in the Crohn's disease group as a whole. The mean value and distribution of the group of Crohn's disease patients not receiving steroids were not different from those of the healthy control group. In the steroid treated control group no decrease in humoral and cellular chemotaxis was observed.

Controversial data have been reported on the effects of corticosteroids on chemotaxis in vitro. Ward ${ }^{-9}$, using the Boyden chamber technique, showed that the addition of hydrocortisone and/or methylprednisolone in vitro suppressed the polymorphonuclear chemotactic response to complementderived chemotactic factors. This effect appeared to be irreversible and the drugs appeared to act directly on polymorphonuclear cells stabilising lysosomal membranes. ${ }^{7}$

Other reports showed no effect of corticosteroids on in vitro chemotaxis, in humans ${ }^{1011}$ and in rabbit. ${ }^{12}$ Recently Clark et al. ${ }^{13}$ showed that the administration of prednisone to healthy people had no effect on their polymorphonuclear cells chemotaxis tested in vitro.

In the present investigation no difference was found between Crohn's disease patients treated with steroids and those not treated as far as the cellular chemotaxis was concerned, but an impaired serum chemotactic activity was observed in those receiving corticosteroids. A defective generation or an increased consumption of complement derived chemotactic factors could be advanced as a mechanism for these findings. In fact, there is evidence ${ }^{1415}$ demonstrating that $\mathrm{C}^{\prime}$ activation does occur in Crohn's disease, although serum C3 levels are normal or increased. Therefore, an increased consumption of complement derived chemotactic factors could contribute in decreasing the serum chemotactic activity. Such an explanation does not account, however, for the significant difference observed in the Crohn's disease group between treated and untreated patients.

Chemotactic factor inactivators are described in normal subjects. ${ }^{16}$ Their function is to control normal chemotactic response. Cell-directed humoral suppressor substances are present in the serum of patients with sarcoidosis in higher concentration than normal serum ${ }^{17} 18$ and similar findings were reported in Hodgkin's disease ${ }^{19}$ and in lepromatous leprosy. ${ }^{20}$ 
It might, therefore, be speculated that similar factors are present in high concentration in the serum of Crohn's disease patients, particularly in those receiving steroid treatment.

In summary, the present results suggest that a defective complement derived serum chemotactic activity may occur in some patients during steroid treatment. These findings may offer an explanation for the therapeutic effect of corticosteroids in Crohn's disease. On the other hand, as already speculated by Segal and Loewi, ${ }^{2}$ they suggest that steroid treatment might play a role in promoting chronicity.

Additional studies are necessary on the possible relationship between chemotactic function, medical treatment, and the natural history of Crohn's disease.

The authors are much indebted to Professor F Aiuti, Professor Luisa Businco, and Professor A Torsoli for their helpful criticisms and advice.

\section{References}

'Ward M. The pathogenesis of Crohn's disease. Lancet 1977; 2: 903-5.

${ }^{2}$ Segal AW, Loewi E. Neutrophil dysfunction in Crohn's disease. Lancet 1976; 2: 219-21.

${ }^{3}$ Rhodes JM, Jewell DP. White cell chemotaxis in Crohn's disease and ulcerative colitis. Gut 1979; 20 : A436.

${ }^{4}$ D'Amelio R, Le Moli S, Rossi P, Aiuti F. Neutrophil chemotaxis defect in IgA deficiency evaluated by migration agarose method. Scand J Immunol 1980; 11: 471-1.

${ }^{5}$ D'Amelio R, Rossi P, Le Moli S, Aiuti F. Defective neutrophil chemotaxis in hypogamma-globulinemia and selective IgA deficiency. Clin Immunol Immunopathol 1980; 16: 287-96.
${ }^{6}$ Best WR, Becktel JM, Singleton JW, Kern F. Development of a Crohn's disease activity index. Gastroenterology 1976; 70: 439-43.

${ }^{7}$ Ward PA. The chemosuppression of chemotaxis. J Exp Med 1966; 124: 209-25.

${ }^{8}$ Ward PA. Chemotaxis of polymorphonuclear leukocytes. Biochem Pharmacol Suppl 1968; 99-105.

${ }^{9}$ Ward PA, Leukotactic factors in health and disease. Am.J Pathol 1971; 64: 521-30.

${ }^{10}$ Sorkin E, Stecher VJ, Borel JF. Chemotaxis of leukocytes and inflammation. Ser Haematol 1970; 3: 131-5.

"Losito A, Gwyn Williams D, Cooke G, Harris L. The effect on polymorphonuclear leucocyte function of prednisolone and azathioprine and 6- mercaptopurine in vitro. Clin exp Immunol 1978; 32: 423-9.

${ }^{12}$ Borel JF. Effect of some drugs on the chemotaxis of rabbit neutrophils in vitro. Experimentia 1973; 29: 676-83.

${ }^{13}$ Clark RAF, Gallin JI, Fauci A. Effects of in vivo prednisone on in vitro eosinophil and neutrophil adherence and chemotaxis. Blood 1979; 53: 633-41.

${ }^{14}$ Hodgson HJF, Potter BJ, Jewell DP. Humoral immune system in inflammatory bowel disease: I Complement levels. Gut 1977; 18: 749-53.

${ }^{15}$ Hodgson HJF, Potter BJ, Jewell DP. C3 metabolism in ulcerative colitis and Crohn's disease. Clin Exp Immunol 1977; 28: 490-5.

${ }^{16}$ Berenberg JL, Ward PA. The chemotactic factor inactivator in normal human serum. $J$ Clin Invest 1973; 52: 1200-6.

${ }^{17}$ Kantor FS, Dwyer JM. Sarcoid. J Invest Derm 1976; 67: 470-6.

${ }^{18}$ Gange RW, Black MM, Carrington P, McKerron R. Defective neutrophil migration in sarcoidosis. Lancet 1977; 2: 379-81.

${ }^{19}$ Ward PA, Berenberg JL. Defective regulation of inflammatory mediators in Hodgkin's disease: supernormal levels of chemotactic factor inactivator. $N$ Engl J Med 1974; 290: 76-80.

${ }^{20}$ Ward PA, Goralnick S, Bullock WE. Defective leukotaxis in patients with lepromatous leprosy. J Lab Clin Med 1976; 87: 1025-32. 